\title{
PERANCANGAN APLIKASI PENJUALAN AKSESORIS ANAK MILENIAL BERBASIS WEB STUDI KASUS : UNIT BISNIS FIKOM UMI
}

\author{
Prawita Simarmata1, Darwis Robinson Manalu², Jhoni Maslan Hutapea ${ }^{3}$ \\ 1,2,3 Program Studi Sistem Informasi Fakultas Ilmu Komputer Universitas Methodist Indonesia \\ ${ }^{1}$ prawitasimarmata4@gmail.com, ${ }^{2}$ manaludarwis@gmail.com,
}

\begin{abstract}
Technological progress in the Millennial Era is very fast, especially in the business world, it has a very large effect. Information technology is currently growing in line with the needs of millennial children who want convenience. So every college wants to achieve a goal. So to achieve this goal, higher education institutions encourage to establish a Business Unit of the Faculty of Computer Science, Indonesian Methodist University (FIKOM UMI). Therefore we need a system that aims to improve the development of an entrepreneurial culture and improve the academic community. By overcoming these problems, a web-based millennial child accessories sales application was designed by applying the FCFS (First Come First Served) method. The millennial generation is currently a major player in the Indonesian economy. So in the business context, it is very important to understand the millennial character so that they can read product trends that are currently popular. One of the products that can show a person's character is accessories. The results obtained are intended to make it easier for customers to order and purchase a variety of accessories products and prioritize customers who are required to pay then the goods are sent and processed first. The system is built using the HTML and PHP programming languages, and the server uses Xampp and the database uses MySql.
\end{abstract}

Keywords-Sales, Accessories, FCFS, MySql, Php

\section{PENDAHULUAN}

Perkembangan Teknologi di Era Milenial sangatlah pesat mampu memberikan efek yang cukup besar, apa lagi dalam dunia bisnis. Kemajuan Teknologi Informasi saat ini terus berkembang seiring dengan kebutuhan anak milenial yang menginginkan kemudahan, dalam memperoleh informasi terutama Fakultas Ilmu Komputer Universitas Methodist Indonesia yang membutuhkan Unit Bisnis Untuk meningkatkan pengembangan Budaya Kewirausahaan. Unit Bisnis Fakultas Ilmu Komputer Universitas Methodist Indonesia (FIKOM UMI) belum memiliki sistem, sehingga masalah tersebut menjadi suatu inspirasi bagi penulis untuk merancang aplikasi penjualan aksesoris anak milenial untuk unit bisnis Fakultas Ilmu Komputer Universitas Methodist Indonesia. Generasi milenial saat ini merupakan pemain utama dalam ekonomi Indonesia. Sehingga dalam konteks bisnis sangat penting untuk memahami karakter milenial agar dapat membaca tren produk yang sedang digemari. Salah satu produk yang dapat menunjukan karakter seseorang adalah aksesoris. Penjualan aksesoris anak milenial seperti kalung, cincin, gelang, anting, souvenir. Pada proses penjualan aksesoris, transaksi dihitung dan dicatat kedalam sistem. Dengan sistem antrian yang dibuat mampu membantu perusahaan dalam mempercepat pekerjaan dalam proses pengolahan data transaksi, dengan menggunakan Metode FCFS (First Come First Served). Selanjutnya nota dikumpulkan untuk dilakukan penyimpanan data kedalam dokumen.

Hal tersebut kurang efisien karena dapat menyebabkan hilangnya data yang tersimpan dalam dokumen. Dengan adanya ini dapat mempermudah Unit Bisnis dalam melakukan transaksi Penjualan kepada konsumen. Oleh karena itu kemajuan teknologi informasi harus terus di upayakan dan ditingkatkan tanpa batasan tempat dan waktu, sehingga semua orang dapat mengakses informasi tersebut terutama dalam penjualan. Penjualan dalam bisnis itu sangatlah penting sehingga perlu strategi yang cukup bagus untuk perkembangan bisnis menjadi lebih maju. Pemesanan dan penjualan dalam penelitian ini untuk mendukung terwujudnya sebuah aplikasi yang mampu mengembangkan Unit Bisnis dalam Fakultas Ilmu Komputer Universitas Methodist Indonesia.

\section{METODE PENELITIAN}

Metode pengumpulan data dapat dilakukan dengan cara mengkaji objek terkait dengan topik penelitian.Cara yang dilakukan untuk mendapatkan data objek penelitian tersebut antara lain :

Metode Penelitian Dalam pembuatan sistem ini tentunya peneliti membutuhkan beberapa metode penelitian, diantaranya yaitu:

A. Metode Pengumpulan Data

Metode pengumpulan data yang digunakan dalam penelitian ini adalah sebagai berikut:

Studi Pustaka

Studi pustaka merupakan penelitian dengan menggunakan dan mempelajari buku-buku maupun literatur-literatur yang berhubungan dengan masalah yang diteliti sebagai landasan teori bagi penulis. Hasil yang diperoleh adalah:

1. Jurnal-Jurnal tentang metode FCFS (First Come First Served) pada permasalahan lain.

2. Buku dan internet sebagai sumber yang berkaitan 
dengan metode FCFS (First Come First Served).

\section{B. Analisis dan perancangan}

Menganalisa sistem serta kebutuhan-kebutuhan apa saja yang akan diperlukan untuk unit bisnis Fakultas Ilmu Komputer Universitas Methodist Indonesia. Pada tahap analisis dan perancangan ini adalah tahap bagaimana sistem dapat memenuhi kebutuhan informasi. Untuk dapat memenuhi kebutuhan pengguna, sistem ini akan memerlukan beberapa tahap desain seperti desain input, desain output, desain basis data, dan desain interface. Berikut ini perincian tentang desain input, desain output, desain interface yang akan dibuat adalah sebagai berikut

1. Desain Input, berfungsi untuk memasukan data dan memprosesnya ke dalam format yang sesuai.

2. Desain Output, merupakan tampilan dari hasil inputan yang sudah diproses oleh sistem.

3. Desain interface, sistem ini dibuat untuk mengatur dan mendesain sistem agar memiliki tampilan yang menarik dan dapat menyampaikan informasi dengan baik.

\section{PEMBAHASAN}

\section{A. Analisa Metode}

Algoritma ini merupakan algoritma penjadwalan yang paling sederhana yang digunakan CPU. Dengan menggunakan algoritma ini setiap proses yang berada pada status ready dimasukkan kedalam FIFO queue atau antrian dengan prinsip first in first out, sesuai dengan waktu kedatangannya. Proses yang tiba terlebih dahulu yang akan dieksekusi. Ada empat buah proses yang datang secara bersamaan yaitu pada $0 \mathrm{~ms}$,

P1 memiliki burst time $8 \mathrm{~ms}$,

P2 memiliki burst time $7 \mathrm{~ms}$,

P3 memiliki burst time $10 \mathrm{~ms}$,

Dan P4 memiliki burst time $6 \mathrm{~ms}$, Apabila kita gunakan Algoritma FCFS ini maka analisisnya akan dijelaskan dalam gantt chart sebagai berikut:

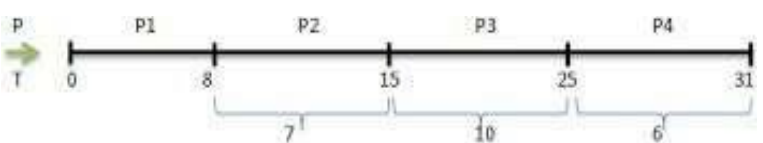

Ket.

$P=$ Process, $T=t$ times

Analisis algoritma FCFS Ketika CPU tidak mengerjakan sesuatu atau dalam posisi 0 datang sebuah proses yang dinamakan P1 yang membutuhkan waktu penyelesaian yang berjumlah 8 . Karena FCFS ini melakukan proses menurut kapan proses itu datang atau yang bisa kita katakan sebagai proses antrian, maka proses selanjutnya akan di kerjakan setelah proses yang berada di depannya selesai untuk di kerjakan. Tadi proses P1 selesai di kerjakan di 8, sementara itu ada P2, P3, dan P4 yang sedang menunggu untuk di kerjakan selanjutnya. Ketika P1 selesai dikerjakan di 8, maka akan di lanjutkan dengan pengerjaan P2 yang memiliki waktu pengerjaan sebesar 7. Sehingga proses P2 akan selesai di kerjakan pada posisi 15.P1 dan P2 sudah selesai pengerjaannya, tinggal menunggu pengerjaan dari pada P3 dan P4. Dan begitupun selanjutnya sampai $\mathrm{P} 4$ selesai untuk di proses.Maka Rata - rata Turn Around Time $=(8+7+10+6) / 4$

$=7,75$ milidetik

\section{B. Perancangan Sistem}

Perancangan merupakan penggambaran, perencanaan dan pembuatan sketsa yang bertujuan untuk melakukan tahap awal dalam merancang suatu sistem [1].

\section{Use Case Diagram}

Use case diagram digunakan untuk menjelaskan apa yang dilakukan oleh sistem yang akan dibangun dan siapa saja yang berinteraksi dengan sistem[2].

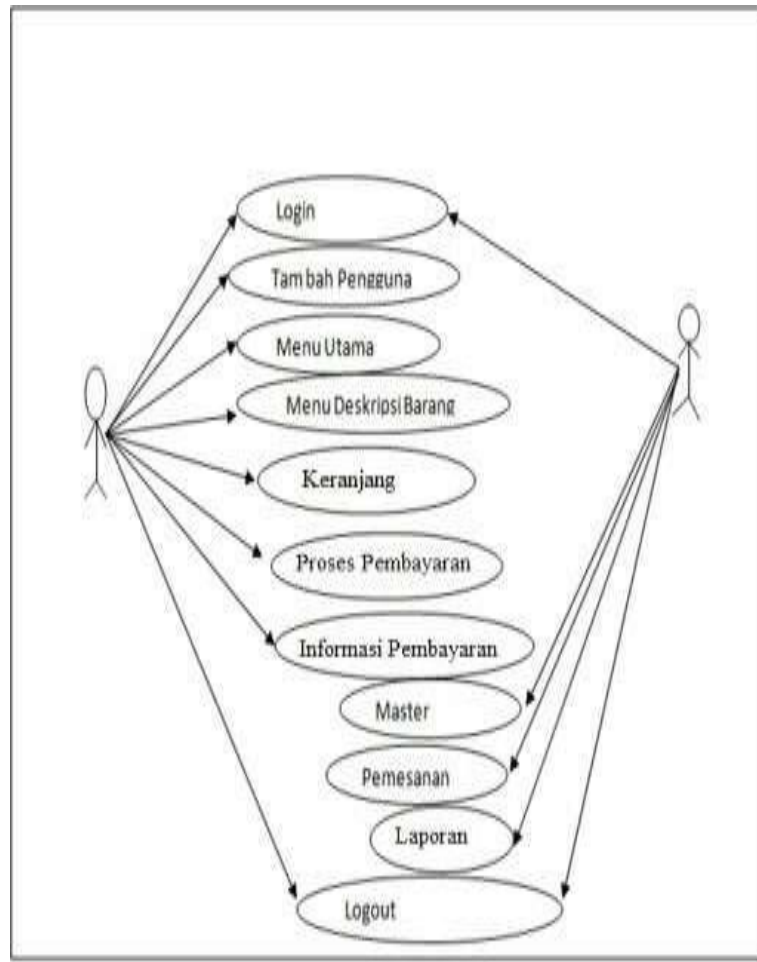

Gambar 1. Use Case Diagram

\section{Transaksi Pemesanan}

Berdasarkan hasil transaksi data Pemesanan terlihat tanggal berapa dan jam berapa barang dipesan dengan menerapkan Metode First Come First Served yaitu yang pertama membayar maka barang akan dikirim dan diproses diluan sehingga yang belum membayar barang dengan sistem transfer melalui rekening tidak dapat diproses dan $10 \%$ dari hasil penjualan barang akan dimasukkan kedalam kas Perusahaan. 
Tabel 1. Hasil Transaksi Pemesanan

\begin{tabular}{|c|c|c|c|c|c|}
\hline $\begin{array}{l}\mathrm{N} \\
\mathrm{O}\end{array}$ & $\begin{array}{l}\text { Kode } \\
\text { Pemesanan }\end{array}$ & $\begin{array}{l}\text { Bukt } \\
\text { i }\end{array}$ & Total Harga & $\begin{array}{l}\text { Konfirmas } \\
\mathrm{i} \\
\text { Pemesana } \\
\mathrm{n}\end{array}$ & $\begin{array}{l}\text { Statu } \\
\mathrm{s}\end{array}$ \\
\hline 1 & $\begin{array}{l}2021062807 \\
\text { 482LEONA } \\
\text { RDO } \\
\text { Tanggal } \\
2021-06-28 \\
12: 51: 56\end{array}$ & lihat & $\begin{array}{l}\text { Rp. } 58.050 \\
\text { Perusahaan } \\
\text { :Rp. } 5.805\end{array}$ & Ya? & $\begin{array}{l}\text { Pros } \\
\text { es... }\end{array}$ \\
\hline 2 & $\begin{array}{l}2021062706 \\
2529 \text { WITA } \\
\text { Tanggal } \\
2021-06-27 \\
23: 26: 02\end{array}$ & & $\begin{array}{l}\text { Rp. } 42.550 \\
\text { Perusahaan : } \\
\text { Rp. } 4.225\end{array}$ & $\begin{array}{l}\text { Belum } \\
\text { Dilakukan } \\
\text { Pembayar } \\
\text { an }\end{array}$ & $\begin{array}{l}\text { Pros } \\
\text { es... }\end{array}$ \\
\hline 3 & 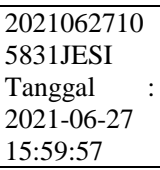 & lihat & $\begin{array}{l}\text { Rp. } 54.100 \\
\text { Perusahaan }\end{array}$ & Batalkan? & $\begin{array}{l}\text { Pros } \\
\text { es... }\end{array}$ \\
\hline
\end{tabular}

\section{PENGUJIAN SISTEM}

\section{A. Pengertian Pengujian Sistem}

Pengujian sistem adalah sederetan pengujian yang berbeda yang tujuan utamnnya adalah sepenuhnya menggunakan sistem berbasis web, salah satu konsep pengujian sistem adalah debugging, debugging terjadi sebagai akibat dari pengujian yang berhasil. Jika test mengungkap kesalahan, maka debugging adalah proses yang menghasilkkan penghilangan kesalahan. Pengujian fokus pada perangkat lunak dan fungsional dan memastikan bahwa semua bagian sudah diuji.Hal ini dilakukan untuk meminimalisir kesalahan (error) dan memastikan keluaran yang dihasilkan sesuai dengan yang diinginkan. Pengujian merupakan bagian yang penting dalam siklus pembangunan perangkat lunak. pengujian dilkaukan untuk menjamin kualitas dan mengetahui kelemahan sistem atau perangkat lunak yang dirancang.

\section{B. Tampilan Program}

\section{Menu Login Admin}

Pada tampilan ini, admin dapat masuk ke sistem dengan menggunakan username dan password

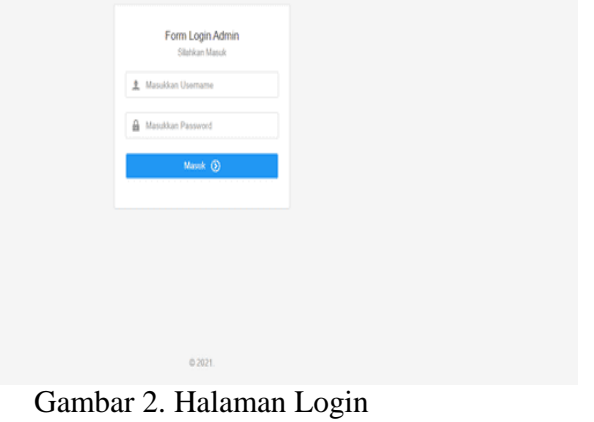

\section{Menu Login Pengguna}

Pada menu login terdapat user name, password dan tombol login

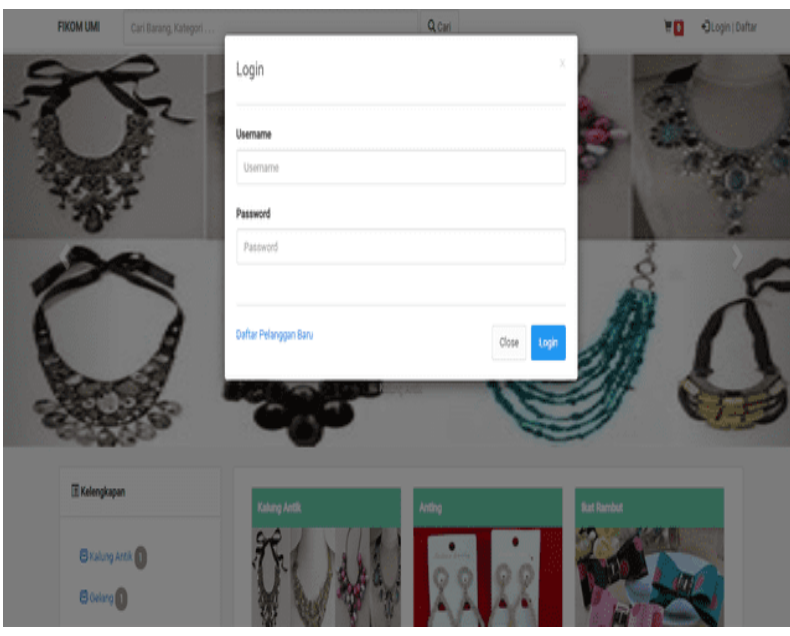

Gambar 3. Menu Login

\section{Menu Daftar Pengguna}

Pada menu daftar pengguna, pengguna di minta untuk mengisi data pengguna. Ada pun data yang perlu di isi adalah sebagai berikut nama pengguna, Alamat, No. Telphone, Alamat Email, Username, Password dan konfirmasi password dan kemudian klik daftar sekarang.

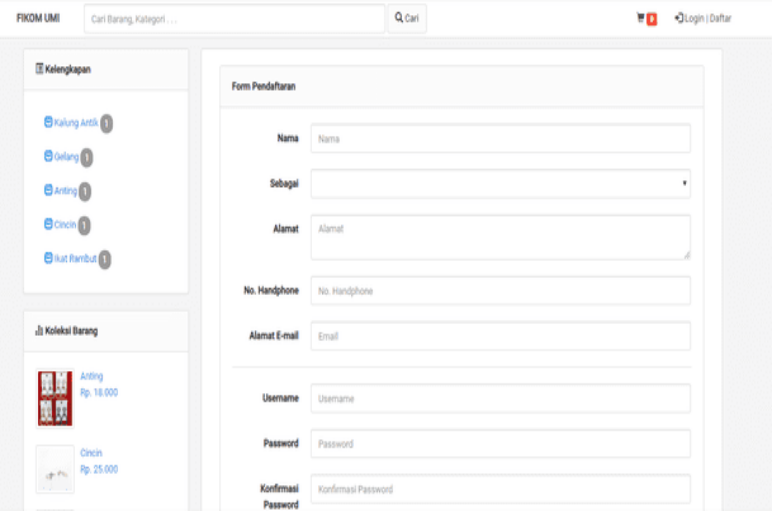

Gambar 4. Menu Daftar Pengguna

\section{Menu Utama}

Pada menu utama terdapat pilihan gambar produk yang hendak di pilih oleh pengguna yang di jual pada Unit Bisnis ini

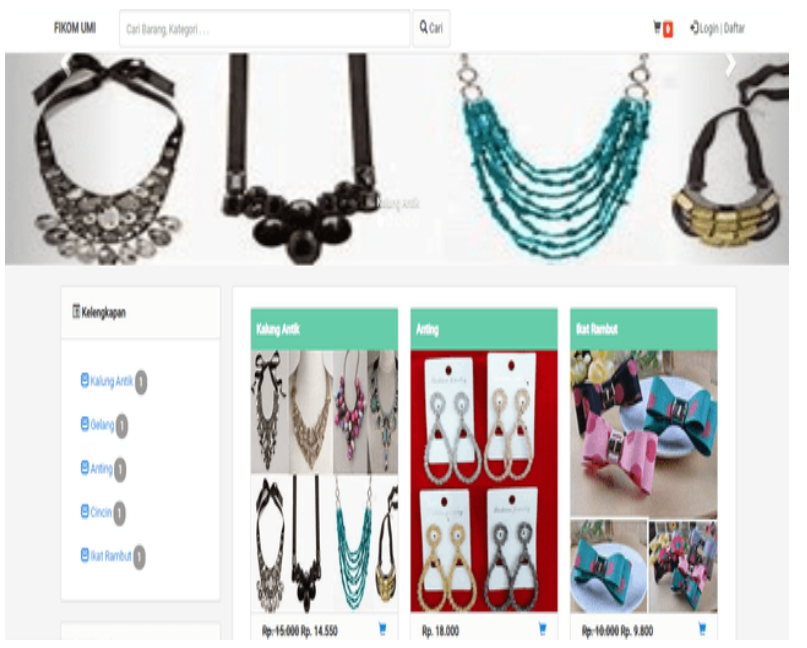




\section{Gambar 5. Menu Utama}

\section{Menu Deskripsi Barang}

Pada menu ini ada nama barang kategori barang, jumlah Stok barang yang tersisa dan deskripsi barang yang mau dibeli kemudian ada tombol beli dan dibawah ada gambar barang barang yang sering di beli.

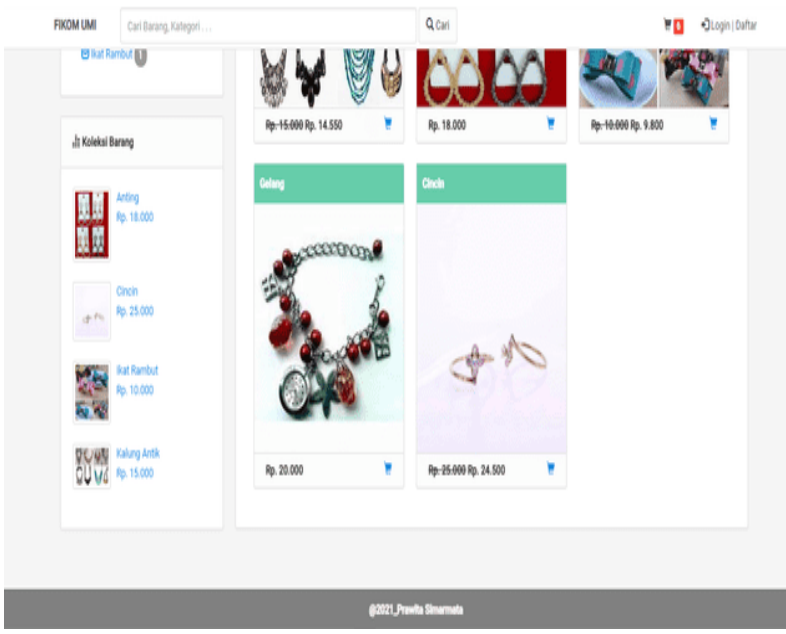

Gambar 6. Menu Deskripsi Barang

\section{Menu Keranjang Belanja}

Pada menu keranjang belanja ini terdapat no pembelian, nama barang, stok, jumlah pesanan, harga barang serta total harga dan tanggal pembelian serta tombol bayar sekarang

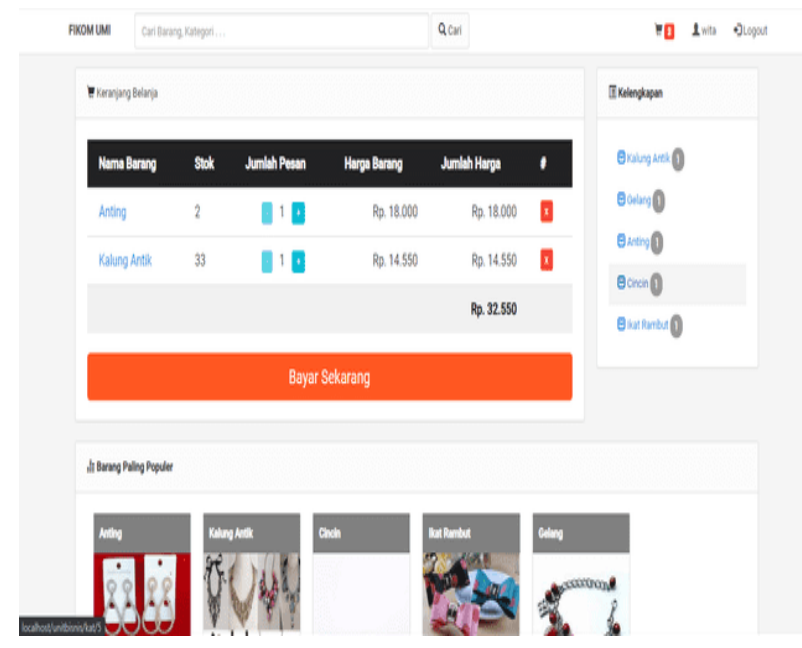

Gambar 7. Menu Keranjang Belanja

\section{Menu Proses Pembayaran}

Pada menu proses pembayaran ada kode pemesanan, nama, alamat, nama barang, jumlah barang mau di beli, harga dan jumlah harga

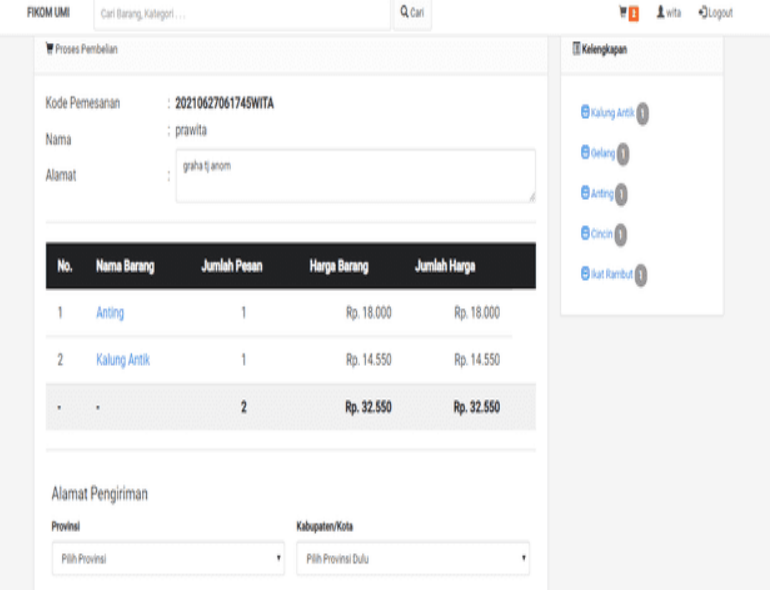

Gambar 8. Menu Proses Pembayaran

\section{Menu Laporan Pelanggan}

Pada menu laporan pelangan terdapat nama-nama data pelangan yang pernah membeli dan login pada website Unit bisnis ini.

\section{Laporal Data Pelangen}

\begin{tabular}{|c|c|c|c|c|c|}
\hline li & Vianilowill & diewilanl & 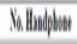 & Ithanil & Tiplitar \\
\hline 1 & Sistat & 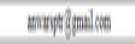 & 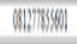 & patent & WHWNWWWO \\
\hline ? & andik & 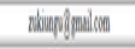 & MEDI/16878 & iktar & 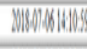 \\
\hline 1. & 4 & ingentiat & 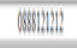 & $y$ & 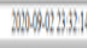 \\
\hline 1 & Shan & mes/fplowaxis & MBOWWW & 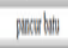 & MUWDONAS \\
\hline 1 & Ailis & 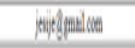 & Witis:40y & atdu & 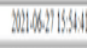 \\
\hline 6 & 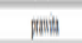 & 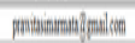 & 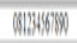 & ptaten & 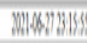 \\
\hline
\end{tabular}

Gambar 10. Menu Laporan Pelanggan

\section{KESIMPULAN}

Aplikasi Penjualan Aksesoris dilengkapi dengan fitur Daftar pelanggan, Pemesanan, Pembayaran melalui rekening, Report, Aplikasi penjualan accessories ini terdapat Discount. Pada Sistem memperoleh keuntungan dari hasil barang yang dijual $10 \%$ untuk perusahaan,terdapat biaya pengiriman barang serta estimasi lama pengiriman. Sehingga dengan menggunakan metode First Come First Served pelanggan yang diluan membayar maka terlebih dahulu dikirim barang dan diproses diluan

\section{REFERENSI}

[1] Nur Fitro (2017). Perancangan Sistem Informasi Penjualan Online pada UKM Industri Monel Desa Kriyan Jepara. Jurnal Informatika Vol.3 No.1

[2] Kuswandi agri (2019). Implementasi Metode First Come First Served pada aplikasi self service order berbasis web. 
[3] Ardi Rizki dan Winarno Agus (2017). Sistem Informasi penjualan aksesoris berbasis online pada CV.Wiratama Semarang.

[4] Okvaniar Sindi (2018). Sistem Informasi pendapatan jasa penyewaan hanbok dengan metode FCFS (studi kasus : Nuna Line Planet)

[5] Wandana catur dita ( 2013), Perancangan sistem informasi penjualan pada Ud.Warso Furnicture menggunakan aplikasi php dan mysql.

[6] Rini Eka Yulia (2017). Perancangan Program Penjualan Perhiasan Emas pada Toko Mas dan Permata Renny Medan.

[7] Fandora Rizky (2013), Perancangan sistem informasi penjualan, pemesanan dan pembelian pada toko cahaya murni silver pacitan.

[8] Alwalidah, Iffah. (2017). Tabayyun Di Era Generasi Millenial. Jurnal Living Hadis, Volume 2, No 1

[9] Ranuharia fadhli (2014), Perancangan sistem informasi jasa penjualan barang berbasis web untuk civitas akademika.

[10] Destiana Henny dan Hadidah annisa (2016). Sistem Informasi Penjualan Accessories berbasis web pada toko fahmi jakarta Vol.XVIII No.1

[11] A. K. D. Sistem, "SISTEM INFORMASI MARKETPLACE PENYEWAAN PROPERTI,” vol. 8, pp. 92-99, 2018.

[12] I. B. Sembiring, D. R. Manalu, S. Sitepu, and J. Maslan, "Perancangan Aplikasi Marketplace Pemesanan Jasa Tukang Kunci Berbasis Android," vol. 1, no. 1, pp. 1-6, 2021. 